DE

M E D I C I N A

T R O P I C A L

$\mathrm{DE}$

SÃO PAULO

JOURNAL OF THE SÃO PAULO INSTITUTE OF TROPICAL MEDICINE

(1) Universidade de São Paulo, Faculdade de Medicina, Departamento de Moléstias Infecciosas e Parasitárias, São Paulo, SP, Brazil.

(2) Fundação Oswaldo Cruz, Laboratório de Tecnologia Virológica Bio-Manguinhos, Rio de Janeiro, RJ, Brazil.

(3) Instituto Butantan, Hospital Vital Brazil, São Paulo, SP, Brazil.

(4) Universidade de São Paulo, Faculdade de Medicina, Departamento de Medicina Preventiva, São Paulo, SP, Brazil.

(5) Universidade de São Paulo, Faculdade de Medicina, Divisão de Imunologia Clínica e Alergia, São Paulo, SP, Brazil.

Correspondence to: Karina Takesaki Miyaji.

Universidade de Sao Paulo, Faculdade de Medicina, Departamento de Moléstias Infecciosas e Parasitárias, Av. Dr, Eneas de Carvalho Aguiar, 155, CEP 05403 000, São Paulo, SP, Brazil.

E-mail: karinamiyaji@gmail.com

Received: 27 January 2016

Accepted: 22 September 2016

\section{Prevalence and titers of yellow fever virus neutralizing antibodies in previously vaccinated adults}

Karina Takesaki Miyaji', Vivian lida Avelino-Silva1, Marisol Simões ${ }^{2}$, Marcos da Silva Freire ${ }^{2}$, Carlos Roberto de Medeiros $^{3}$, Patrícia Emilia Braga ${ }^{4}$, Maria Angélica Acalá Neves ${ }^{5}$, Marta Heloisa Lopes ${ }^{1}$, Esper Georges Kallas ${ }^{5}$, Ana Marli Christovam Sartori ${ }^{1}$

\section{ABSTRACT}

Introduction: The World Health Organization (WHO) recommends one single dose of the Yellow Fever (YF) vaccine based on studies of antibody persistency in healthy adults. We assessed the prevalence and titers of YF virus neutralizing antibodies in previously vaccinated persons aged $\geq 60$ years, in comparison to younger adults. We also evaluated the correlation between antibody titers and the time since vaccination among participants who received one vaccine dose, and the seropositivity among participants vaccinated prior to or within the past 10 years. Methods: previously vaccinated healthy persons aged $\geq 18$ years were included. YF virus neutralizing antibody titers were determined by means of the $50 \%$ Plaque Reduction Neutralization Test. Results: 46 persons aged $\geq 60$ years and 48 persons aged 18 to 59 years were enrolled. There was no significant difference in the prevalence of YF virus neutralizing antibodies between the two groups $(p=0.263)$. However, titers were significantly lower in the elderly $(p=0.022)$. There was no correlation between YF virus neutralizing antibody titers and the time since vaccination. There was no significant difference in seropositivity among participants vaccinated prior to or within the past 10 years. Conclusions: the clinical relevance of the observed difference in YF virus neutralizing antibody titers between the two groups is not clear.

KEYWORDS: Elderly. Immunization. Neutralizing antibody. Seroprevalence. Yellow fever vaccine.

\section{INTRODUCTION}

Yellow fever (YF) is caused by a Flavivirus transmitted by mosquitos' bites. In the sylvatic cycle, the virus is transmitted by Haemagogus spp and Sabethes spp, and in the urban cycle by Aedes spp. It is a severe acute disease with no available antiviral treatment, and vaccination is the most important preventive measure. Two types of live attenuated vaccines are available, 17DD and 17D-204, both derived from the strain $17 \mathrm{D}^{1}$.

YF disease is an important public health problem in Brazil. During the 2000s the transmission risk area has expanded, causing YF outbreaks in areas that were previously free of YF virus circulation in the South and Southeast of the country ${ }^{2,3,4}$. Nowadays, YF vaccine is recommended for those living in such regions, including the elderly that should receive their primary immunization.

The World Health Organization (WHO) has recently recommended a single lifetime dose of YF vaccine, based on the evidence of long-term immunity ${ }^{5}$. The 
Brazilian Ministry of Health currently recommends two doses of YF vaccine: children under the age of four living in endemic areas should receive the first dose at 9 months, and a second dose at four years of age; persons older than four years should receive two vaccine doses with a 10 year-interval ${ }^{6}$. The YF 17DD vaccine produced by Biomanguinhos (Fundação Oswaldo Cruz, Rio de Janeiro) is used in Brazil.

The elderly population is increasing in Brazil and worldwide. Considering that aging is associated with effects on immunity and vaccine response, particularly in primary vaccination ${ }^{7,8}$, studies to assess the duration of protection conferred by the YF vaccine in this population are necessary.

This study aimed to evaluate the prevalence and titers of YF virus neutralizing antibodies among previously vaccinated persons aged $\geq 60$ years as compared to younger adults. We also tested the correlation between YF virus neutralizing antibody titers and the time since vaccination among adults who received just one dose of the $\mathrm{YF}$ vaccine.

\section{MATERIALS AND METHODS}

\section{Study Population}

This study was conducted at the Reference Center for Special Immunobiologicals (Centro de Referência para Imunobiológicos Especiais, CRIE) of the Hospital das Clínicas da Faculdade de Medicina da Universidade de São Paulo (HC-FMUSP), in São Paulo city, a non-endemic area for YF transmission. We included healthy persons aged $\geq 18$ years who had previously received the YF vaccine, regardless of the number of doses and the time since last vaccination. Healthcare workers and persons who came to CRIE to receive any vaccine were invited to participate. Pregnant women, immunocompromised patients and those with acute febrile conditions were excluded. All the subjects were submitted to two HIV rapid tests (Abbott Determine ${ }^{\mathrm{TM}} \mathrm{HIV}-1 / 2$ and SD Bioline HIV 1/2 fast 3.0) and all non-menopausal women were tested for pregnancy (chorionic gonadotropin test in urine, $\mathrm{ABON}^{\mathrm{TM}} \mathrm{hCG}$ ). Persons with positive or indeterminate tests were excluded. All participants signed an informed consent form. The study was approved by the HC-FMUSP Ethics Committee.

Participants were divided into two groups: persons aged 60 years and more (Group 1) and those aged from 18 to 59 years (Group 2). Data on age, ethnicity, gender, number of previous YF vaccine doses and date of the last YF vaccination were collected.

\section{YF virus neutralizing antibody measurements}

YF virus neutralizing antibody was measured using the Plaque Reduction Neutralization Test (PRNT). The PRNT titer was defined as the reciprocal of the last serum dilution that reduced the number of plaques by 50\% $\left(\mathrm{PRNT}_{50}\right)$. The test was performed in the Virological Technology Laboratory, Bio-Manguinhos, Fundação Oswaldo $\mathrm{Cruz}$, as previous described ${ }^{9}$. In that study, the value of $2.9 \log _{10} \mathrm{mIU} / \mathrm{mL}$ (794 mIU/ $\mathrm{mL}$ or 1:50) provided the best combination of sensitivity and specificity for the PRNT50 test, in the ROC curve ${ }^{9}$. Results $\geq 794 \mathrm{mIU} / \mathrm{mL}$ (equivalent to $2.9 \log _{10} \mathrm{mIU} / \mathrm{mL}$ ) were considered seropositive and results $<794 \mathrm{mIU} / \mathrm{mL}$ were considered seronegative.

\section{Statistical analyses}

A Microsoft Excel database (Microsoft Corp., Redmond, Washington, USA) was built and statistical analysis was performed using SPSS for Windows version 15.0 (SPSS Inc., Chicago, IL, USA) and Epi Info 7 (CDC, Atlanta, GA, USA).

Descriptive analyses of the medians, means, standard deviations and percentages were used to establish the participants demographic and clinical characteristics. YF virus neutralizing antibody titers were $\log _{10}$-transformed for analysis. The chi-square test was used to compare the frequencies of the categorical variables (e.g., gender, ethnicity, number of YF vaccine doses previously taken and YF seropositivity between the groups, and the Student's t-test or Mann-Whitney test were used to compare the continuous variables (time since vaccination, and YF virus neutralizing antibody titers), as appropriate.

Correlation between YF neutralizing antibody titers and the time since vaccination in participants who had previously received only one dose of YF vaccine was described by the Spearman coefficient. The Fisher's Exact test was applied to compare the seroprevalence of YF antibodies in participants who had received just one vaccine dose within ten years and more than ten years before.

Statistical tests were performed with a significance level of $5 \%$.

\section{RESULTS}

From November 2010 to February 2013, 94 volunteers were included, 46 in Group 1 ( $\geq 60$ years old) and 48 in Group 2 (18 to 59 years). Table 1 shows the participants demographic characteristics and the history of YF vaccination. There was no statistically significant difference between the study groups regarding gender 
( $p=0.204)$, ethnicity $(p=0.131)$, number of previous YF vaccine doses $(p=0.146)$ and time elapsed since the last vaccination $(p=0.108)$. Four participants could not provide a vaccination document (two in each group), but the information was considered reliable. None of them lived in endemic areas at the time they were enrolled in the study; and three of the four knew the exact circumstances of vaccination (year and motivation).

Table 2 shows the frequency of YF seropositivity and the $\log _{10}$-transformed Geometric Mean Titer (GMT) of YF virus neutralizing antibodies in both groups. The difference in seropositivity between the groups was not statistically significant. However, $\log _{10}$-transformed antibody titers were significantly lower in the elderly group $(p=0.022)$.

Nine subjects were seronegative for $Y F(<794 \mathrm{mIU} / \mathrm{mL})$, six in Group 1 (mean $=560 \mathrm{mIU} / \mathrm{mL}$ ) and three in Group 2 (of whom two had $\mathrm{PRNT}_{50}$ titers below the limit of 210 $\mathrm{mIU} / \mathrm{mL}$ ). All nine subjects had previous documented YF vaccination (Table 3). Six participants (five in Group
1 and one in Group 2) had been vaccinated within the last 10 years (mean time since vaccination $=26.7$ months and 16.3 months, respectively), whereas three subjects (one in Group 1 and two in Group 2) had been vaccinated more than 10 years before enrollment (mean $=145.4$ months and 141.6 months, respectively). One participant (Group 1) had previously received two doses of YF vaccine and one could not remember how many doses she had received.

Twenty-four participants (10 in Group 1 and 14 in Group 2) had received the YF vaccine more than 10 years before enrollment. Among those, three were seronegative for YF, one in Group 1 (who did not remember how many YF vaccine doses she had previously received) and two in Group 2 (both had received only one YF vaccine dose).

Considering all the subjects who had received a single dose $(n=59)$, there was no correlation between the time elapsed since vaccination and GMT $\left(\rho_{\text {Spearman }}=-0.0804\right.$, $p=0.56$ ) as shown in Figure 1.

There was also no statistically significant difference in seropositivity among participants of all ages who received

Table 1 - Demographic characteristics and history of yellow fever vaccination of participants aged 60 years or more (Group 1) and under-60 years (Group 2).

\begin{tabular}{|c|c|c|c|}
\hline & $\begin{array}{c}\text { Group } 1(\geq 60 y) \\
n=46 \\
n^{\circ}(\%)\end{array}$ & $\begin{array}{c}\text { Group } 2(18-59 y) \\
n=48 \\
n^{\circ}(\%)\end{array}$ & $p$-value \\
\hline \multicolumn{4}{|l|}{ Age } \\
\hline $\begin{array}{l}\text { Mean (SD) } \\
\text { Median (min - max) }\end{array}$ & $\begin{array}{c}70.0(6.5) \\
68.5(60-85)\end{array}$ & $\begin{array}{c}35.6(9.9) \\
33.0(20-58)\end{array}$ & - \\
\hline \multicolumn{4}{|l|}{ Gender } \\
\hline Female & $30(65.2)$ & $37(77.1)$ & 0.204 \\
\hline \multicolumn{4}{|l|}{ Race } \\
\hline $\begin{array}{l}\text { Caucasian } \\
\text { African } \\
\text { Asian } \\
\text { Indigenous }\end{array}$ & $\begin{array}{c}30(65.2) \\
10(21.7) \\
5(10.9) \\
1(2.2)\end{array}$ & $\begin{array}{l}38(79.2) \\
6(12.6) \\
4(8.3) \\
0(0.0)\end{array}$ & $0.131^{*}$ \\
\hline \multicolumn{4}{|c|}{ Number of previous doses of Yellow Fever vaccine $(n=76)^{\star \star}$} \\
\hline $\begin{array}{l}1 \\
\geq 2 \\
\text { Unknown }(\geq 1)\end{array}$ & $\begin{array}{l}23(50.0) \\
10(21.7) \\
13(28.3)\end{array}$ & $\begin{array}{l}36(75.0) \\
7(14.6) \\
5(10.4)\end{array}$ & 0.146 \\
\hline \multicolumn{4}{|c|}{ Time elapsed since last dose (months) $(n=93)^{\#}$} \\
\hline $\begin{array}{l}\text { Mean (SD) } \\
\text { Median }(\min -\max )\end{array}$ & $\begin{array}{c}60.9(52.3) \\
40.0(3.4-232.3)\end{array}$ & $\begin{array}{c}80.2(57.1) \\
69.3(1.7-246.3)\end{array}$ & 0.108 \\
\hline \multicolumn{4}{|c|}{ Age at last vaccination $(n=93)^{\#}$} \\
\hline $\begin{array}{l}\text { Mean (SD) } \\
\text { Median (min-max) }\end{array}$ & $\begin{array}{c}65.3(7.0) \\
64.9(50.0-83.1)\end{array}$ & $\begin{array}{c}29.3(9.8) \\
27.6(10.6-54.5)\end{array}$ & \\
\hline \multicolumn{4}{|c|}{ Time elapsed since last vaccination } \\
\hline $\begin{array}{l}\leq 10 \text { years } \\
>10 \text { years }\end{array}$ & $\begin{array}{l}36(78.3) \\
10(21.7)\end{array}$ & $\begin{array}{l}34(70.8) \\
14(29.2)\end{array}$ & \\
\hline
\end{tabular}

${ }^{*}$ Analysis comparing caucasian and non-caucasian persons. ** Analysis excluded persons that did not know how many doses they received. "One person was excluded of the analysis because she did not know when she received the vaccine. 
Table 2 - Seroprevalence and log-transformed geometric mean titers of Yellow Fever (YF) neutralizing antibody (Ab) measured by Plaque Reduction Neutralization Test (PRNT ${ }_{50}$ ) among participants aged 60 years or more (Group 1) and under-60 years (Group 2).

\begin{tabular}{|c|c|c|c|}
\hline & $\begin{array}{c}\text { Group } 1(\geq 60 y) \\
n=46 \\
n^{\circ}(\%)\end{array}$ & $\begin{array}{c}\text { Group } 2(18-59 y) \\
n=48 \\
n^{\circ}(\%)\end{array}$ & $p$-value \\
\hline \multicolumn{4}{|c|}{ Seroprevalence (neutralizing $\mathrm{Ab}, \mathrm{mIU} / \mathrm{mL}$ ) } \\
\hline $\begin{array}{l}\text { Positive } \\
\text { Negative }\end{array}$ & $\begin{array}{l}40(87.0) \\
6(13.0)\end{array}$ & $\begin{array}{c}45(93.8) \\
3(6.3)\end{array}$ & 0.263 \\
\hline \multicolumn{4}{|c|}{ YF neutralizing Ab titer $(\log 10 \mathrm{mlU} / \mathrm{mL})(\mathrm{n}=88)^{\star}$} \\
\hline $\begin{array}{l}\text { Mean (SD, CI 95\%) } \\
\text { Median (min - max) }\end{array}$ & $\begin{array}{c}3.44(0.43,3.35-3.53) \\
3.48(2.38-4.28)\end{array}$ & $\begin{array}{c}3.64(0.36,3.56-3.71) \\
3.67(2.77-4.27)\end{array}$ & 0.022 \\
\hline
\end{tabular}

\# Cutoff $=794 \mathrm{mlU} / \mathrm{mL}$, equivalent of $2.9 \log _{10} \mathrm{mlU} / \mathrm{mL}$.

*Participants without exact titer were excluded from this analysis (four with results above the upper limit of the test and two below the lower limit of the test).

Table 3 - Characteristics of the subjects seronegative for yellow fever.

\begin{tabular}{|c|c|c|c|c|}
\hline Subject & $\begin{array}{l}\text { Age / Age at the moment } \\
\text { of vaccination }\end{array}$ & Gender & $\begin{array}{c}\text { Number of previous } \\
\text { doses }\end{array}$ & $\begin{array}{c}\text { Time elapsed since last } \\
\text { dose (months) }\end{array}$ \\
\hline 1 & $68 / 64.89$ & $F$ & 1 & 40.23 \\
\hline 2 & $81 / 78.25$ & $\mathrm{~F}$ & 1 & 40.03 \\
\hline 3 & 69 / 68.75 & $\mathrm{~F}$ & 2 & 3.40 \\
\hline 4 & $68 / 66.46$ & M & 1 & 24.30 \\
\hline 5 & 65 / 63.22 & $\mathrm{~F}$ & 1 & 22.33 \\
\hline 6 & $70 / 58.73$ & $\mathrm{~F}$ & Unknown $(\geq 1)$ & 145.37 \\
\hline 7 & $45 / 44.10$ & $\mathrm{~F}$ & 1 & 16.63 \\
\hline 8 & $37 / 25.05$ & $\mathrm{~F}$ & 1 & 141.87 \\
\hline 9 & $33 / 21.16$ & $\mathrm{~F}$ & 1 & 141.40 \\
\hline
\end{tabular}

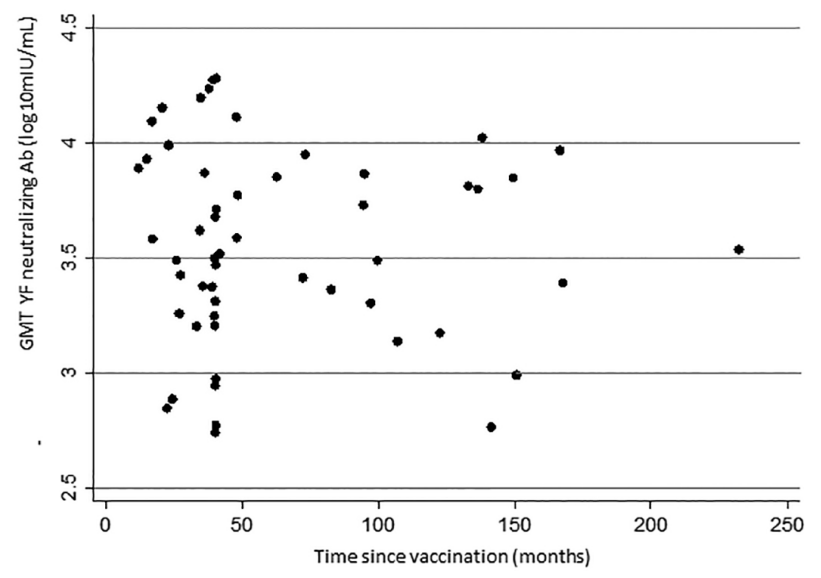

Figure 1 - Scatter plot of Yellow Fever neutralizing antibody titers $(\log 10 \mathrm{mIU} / \mathrm{mL})$ measured by $50 \%$ Plaque Reduction Neutralization Test (PRNT ${ }_{50}$ ) and time elapsed since vaccination in participants who had received just one dose of YF vaccine.

a single dose of YF vaccine within the last 10 years $(n=46)$ and those immunized more than 10 years before enrollment $(\mathrm{n}=13, p=0.9723)$.

\section{DISCUSSION}

The present study evaluated 94 subjects previously vaccinated for YF to evaluate the antibody seropositivity in the elderly ( $\geq 60$ years of age) in comparison with younger adults (18-59 years of age). YF virus neutralizing antibody titers were measured by $\mathrm{PRNT}_{50}$, a sensitive and specific test to quantify YF virus neutralizing antibodies ${ }^{10}$. Older and younger adults had similar time elapsed since the last vaccination, and seropositivity was not significantly different between the groups. However, $\log _{10}$-transformed titers of neutralizing antibodies were slightly lower among older adults compared to the younger ones (3.64 vs. $3.77 \log _{10} \mathrm{mIU} / \mathrm{mL}, p=0.022$ ). The clinical relevance of this difference is unclear, since titers in both groups are high; it is unlikely that this difference will result in altered immunity to YF.

Aging of the human immune system, or immunosenescence, is characterized by changes in the innate and adaptive immune responses including decreased hematopoietic stem cells proliferation capacity, reduction 
in lymphoid precursors cells and increase in myeloid precursors cells. Consequently, older subjects usually present with quantitative and qualitative reduction in antigen presenting cells. Additionally, the adaptive response is affected by aging through thymus involution, with lower populations of naïve $\mathrm{T}$ and $\mathrm{B}$ lymphocytes and predominance of memory and effectors cells. These changes lead to a reduction in cell receptors repertoire and a decreased responsiveness to new antigens, such as primary vaccination ${ }^{7,8}$.

Our results of similar seropositivity between the two groups is compared to other studies that evaluated seroconversion after YF vaccination in the elderly. Roukens et al. ${ }^{11}$ compared YF virus neutralizing antibody titers between elderly (from 60 to 81 years, median 66 years) and a younger group (from 18 to 28 years, median 21 years) before, and 10 and 28 days after YF vaccination. They used a variation of the PRNT method and titers $\geq 500 \mathrm{mIU} / \mathrm{mL}$ were considered protective. Ten days after vaccination, $50 \%$ of older adults were seropositive, as compared to $77 \%$ of the younger group and GMT was $2.9 \mathrm{IU} / \mathrm{mL}$ lower in the elderly group. However, 28 days after vaccination, the difference between the two groups disappeared, suggesting that the elderly have a slower response but, ultimately, a response that is quantitatively similar to the younger group. Long-term persistency of protection was not evaluated in this study.

Monath et al. ${ }^{12}$ evaluated the immunogenicity of a single dose of YF vaccine in younger (18 to 44 years old) and older ( $\geq 60$ years old) adults, using a constant serumvarying virus plaque-reduction test. A $\log _{10}$ neutralization index (LNI $\geq 0.7$ thirty days after vaccination was considered protective. There was no difference between the two study groups. These studies showed no difference in seroconversion between the elderly and young persons, but they did not evaluate the long-term antibody persistence.

Gotuzzo et al. performed a systematic review of efficacy, duration of protection and the need of booster doses of YF vaccine ${ }^{13}$. They found a long-term persistency of YF antibody in healthy persons, with $>90 \%$ seropositivity at 20 years after vaccination, and up to $80 \%$ of antibody persistency at 35 years after vaccination. Only one study included in this review ${ }^{14}$ evaluated persons $\geq 60$ years old, who had received the vaccine $\geq 10$ years before enrollment and had some contraindication to be revaccinated $(n=84)$, showing seropositivity in $95.2 \%$. This result contrasts with the $87 \%$ seropositivity found in our study. Another Brazilian study evaluated previously vaccinated persons aged 18 to 83 year-old, describing $93.9 \%$ of seropositivity 1 to 4 years after vaccination; $83.1 \%, 5$ to 9 years; $76.1 \%, 10$ to 11 years; and $85.3 \%, \geq 12$ years $^{15}$.
In our study, there was no statistically significant difference in seropositivity between the subjects who had received a single dose of YF vaccine within the last 10 years (median 39.8 months) and more than 10 years (median 149.3 months) before enrollment. This result is similar to those found in other studies that evaluated antibody persistence ${ }^{16,17,18}$. However, we had few participants who had received a single vaccine dose $(n=59)$ and that received the YF vaccine more than 10 years before enrollment $(\mathrm{n}=23)$.

Nine out of 94 participants were seronegative for YF. This is a relevant finding, suggesting that a significant proportion of vaccinees are actually not protected against YF. Six of the nine seronegative subjects were vaccinated less than ten years prior to enrollment suggesting failure to seroconvert. There were 5 seronegative among 36 (13.89\%) persons aged more than 60 years and only one seronegative among $34(2.94 \%)$ persons aged less than 60 years. In spite of the small sample, this finding suggests that the elderly may have a higher rate of failure to seroconvert after vaccination. Accordingly, cases of vaccine failure have been reported. In Brazil, Tuboi et al. ${ }^{19}$ reviewed five cases of YF in subjects with documented vaccination, leading to two deaths. They were between the ages of 17 to 62 years and the time elapsed since vaccination varied from 5 to 62 months. Gotuzzo et al..$^{13}$ described five additional cases, with three deaths, in persons who had been vaccinated from 15 months to five years before the disease development. In both studies, the short time between vaccination and disease suggests primary vaccine failure.

Seroconversion rates after vaccination, waning immunity and primary vaccine failure are important factors to be considered when recommending a single dose of YF vaccine, particularly in endemic areas. Our study did not find any correlation between the time elapsed since vaccination and $\mathrm{YF}$ virus neutralizing antibody titers among subjects who had received a single dose of YF vaccine.

This study has some limitations. We had a small sample size. We cannot exclude that exposure to wild YF plays a role as a natural booster, preventing the reduction of YF virus neutralizing antibody titers over time, although none of the subjects lived in endemic areas. We cannot rule out that some participants received more vaccine doses than reported, since large vaccine campaigns have been conducted in the country in recent years, and we expect the vaccine documentation to be imperfect in this context. In the elderly group, eight (17.4\%) were vaccinated before the age of 60 , and it was not possible to analyze separately the subjects who had received the vaccine before and after 60 years of age due to the small sample size. We included four subjects without the vaccine documentation because the information given was considered 
reliable and losing the vaccine document is very frequent. All four were seropositive for YF antibody. Other studies have also included persons with only the verbal report of vaccination $^{14,16}$.

In conclusion, this study found no difference in seropositivity between elderly and younger subjects and no correlation between the time since vaccination and YF virus antibody titers. Even though, the finding of nine seronegative subjects, six of them aged more than 60 years, may represent failure to seroconvert. Our findings support the Health Ministry decision of recommending two doses of YF vaccine instead of the WHO recommendation of a single vaccine dose. More studies including the elderly, persons with comorbidities and immunocompromised patients living in endemic areas are necessary to address whether response to YF vaccination is weaker or of shorter duration in these population groups.

\section{ACKNOWLEDGMENTS}

We would like to thank the staff of the Centro de Pesquisa Clínica - HCFMUSP and CRIE HCFMUSP, who helped to identify participants and collect blood samples, and Laboratório de Investigação Médica (LIM) 60, Flow Cytometry Laboratory, Instituto Adolfo Lutz and the Virological Technology Laboratory, Bio-Manguinhos, Fundação Oswaldo Cruz for performing the laboratory tests.

\section{CONFLICT OF INTEREST}

AMCS received speaker fees from Sanofi Pasteur. The other authors declared no conflicts of interest.

\section{REFERENCES}

1. Monath TP, Gershman M, Staples JE, Barrett AD. Yellow fever vaccine. In: Plotkin SA, Orenstein WA, Offit PA, editors. Vaccines. 6th ed. Edinburgh: Elsevier/Saunders; 2013. p.870968.

2. Mascheretti M, Tengan CH, Sato HK, Suzuki A, Souza RP, Maeda $\mathrm{M}$, et al. Yellow fever: reemerging in the the state of Sao Paulo, Brazil, 2009. Rev Saude Publica. 2013;47:881-9.

3. Brasil. Ministério da Saúde. Secretaria de Vigilância em Saúde. Aspectos epidemiológicos da febre amarela silvestre e a vigilância intensificada durante período de monitoramento, Brasil, 2012/2013. Bol Epidemiol. 2014 [cited 2016 Jun 22];45:1-2. Available from: http://u.saude.gov.br/images/ pdf/2014/maio/27/BE-V45-n---07-FebreAmarela.pdf

4. Monath TP, Vasconcelos PF. Yellow fever. J Clin Virol. 2015;64:160-73.
5. World Health Organization. Vaccines and vaccination against yellow fever: WHO Position Paper - June 2013. Wkly Epidemiol Rec. 2013 [cited 2016 Jun 22];88:269-84. Available from: http://www.who.int/wer/2013/wer8827.pdf?ua=1

6. Brasil. Ministério da Saúde. Secretaria de Vigilância em Saúde. Recomendações da vacinação contra febre amarela após a declaração da Organização Mundial da Saúde. [cited 2016 Jun 22]. Available from:http://sbmt.org.br/portal/wp-content/ uploads/2015/02/Nota-Informativa-143-2014-Febre-Amarela.pdf

7. Grubeck-Loebenstein B, Della Bella S, Iorio AM, Michel JP, Pawelec G, Solana R. Immunosenescence and vaccine failure in the elderly. Aging Clin Exp Res. 2009;21:201-9.

8. Goronzy JJ, Weyand CM. Understanding immunosenescence to improve responses to vaccines. Nat Immunol. 2013;14:428-36.

9. Simões M, Camacho LA, Yamamura AM, Miranda EH, Cajaraville AC, da Silva Freire M. Evaluation of accuracy and reliability of the plaque reduction neutralization test (micro-PRNT) in detection of yellow fever virus antibodies. Biologicals. 2012;40:399-404.

10. Niedrig M, Lademann M, Emmerich P, Lafrenz M. Assessment of $\mathrm{IgG}$ antibodies against yellow fever virus after vaccination with 17D by different assays: neutralization test, haemagglutination inhibition test, immunofluorescence assay and ELISA. Trop Med Int Health. 1999;4:867-71.

11. Roukens AH, Soonawala D, Joosten SA, de Visser AW, Jiang $\mathrm{X}$, Dirksen $\mathrm{K}$, et al. Elderly subjects have a delayed antibody response and prolonged viraemia following yellow fever vaccination: a prospective controlled cohort study. PLoS One. 2011;6:e27753.

12. Monath TP, Cetron MS, McCarthy K, Nichols R, Archambault WT, Weld L, et al. Yellow fever 17D vaccine safety and immunogenicity in the elderly. Hum Vaccin. 2005;1:207-14.

13. Gotuzzo E, Yactayo S, Córdova E. Efficacy and duration of immunity after yellow fever vaccination: systematic review on the need for a booster every 10 years. Am J Trop Med Hyg. 2013;89:434-44.

14. Coulange Bodilis H, Benabdelmoumen G, Gergely A, Goujon C, Pelicot M, Poujol P, et al. Persistance à long terme des anticorps neutralisants de la fièvre jaune chez les personnes âgées de 60 ans et plus. Bull Soc Pathol Exot. 2011;104:260-5.

15. Collaborative Group for studies on Yellow Fever Vaccines. Duration of post-vaccination immunity against yellow fever in adults. Vaccine. 2014;32:4977-84.

16. Gómez SY, Ocazionez RE. Anticuerpos neutralizantes contra el virus de la fiebre amarilla $17 \mathrm{D}$ en colombianos vacunados y no vacunados con inmunidad a dengue. Rev Salud Publica (Bogota). 2008;10:796-807.

17. Camacho LA, Freire MS, Leal ML, Aguiar SG, Nascimento JP, Iguchi T, et al. Immunogenicity of WHO-17D and Brazilian 17DD yellow fever vaccines: a randomized trial. Rev Saude Publica. 2004;38:671-8. 
18. Poland JD, Calisher CH, Monath TP, Downs WG, Murphy K. Persistence of neutralizing antibody 30-35 years after immunization with 17D yellow fever vaccine. Bull World Health Organ. 1981;59:895-900.
19. Tuboi SH, Costa ZG, Vasconcelos PFC, Hatch D. Clinical and epidemiological characteristics of yellow fever in Brazil: analysis of reported cases 1998-2002. Trans R Soc Trop Med Hyg. 2007;101:169-75. 